\title{
Malposition of a percutaneous endoscopic gastrostomy tube in the jejunum
}
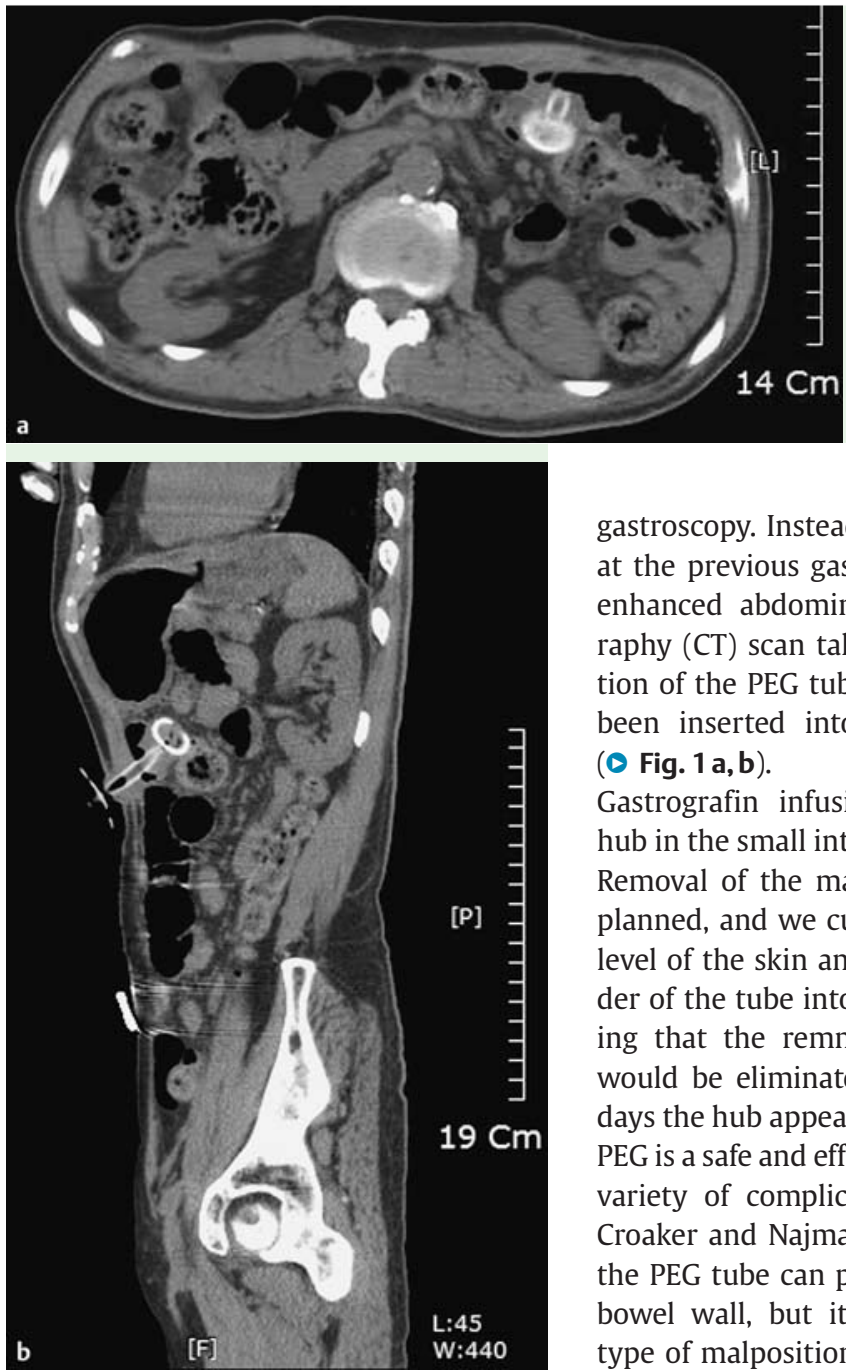

A 75-year-old man attended our hospital for replacement of a percutaneous endoscopic gastrostomy (PEG) tube. He had originally undergone PEG tube placement at our hospital 2 years ago, and after insertion the position of the hub had been checked by gastroscopy. However, placement of the most recent PEG tube had been done at another hospital 1 year ago, with no gastroscopic evaluation. When the patient attended our hospital 1 year later for replacement of the PEG tube, we could not find its hub in the stomach on
Fig. 1 Contrast, nonenhanced abdominal computed tomography (CT) scan showing the percutaneous endoscopic gastrostomy (PEG) tube in the small bowel. a Axial view. b Sagittal view.

gastroscopy. Instead, a scar was detected at the previous gastrostomy site. A nonenhanced abdominal computed tomography (CT) scan taken to check the location of the PEG tube revealed that it had been inserted into the small intestine ( Fig. 1 a,b).

Gastrografin infusion also showed the hub in the small intestine ( $\bullet$ Fig. 2).

Removal of the malpositioned tube was planned, and we cut the PEG tube at the level of the skin and pushed the remainder of the tube into the lumen, anticipating that the remnant of the PEG tube would be eliminated with stool. After 3 days the hub appeared in the stool.

PEG is a safe and effective procedure, but a variety of complications can occur [1]. Croaker and Najmaldin [2] reported that the PEG tube can pass through the small bowel wall, but it is unlikely that this type of malposition would remain undetected and asymptomatic. Treatment involves removal of the PEG tube and repair of the small bowel. Pearce et al. [3] reported safe removal of the tube in $71 / 73$ patients by the cut and push method, without endoscopic support. We conclude that after PEG tube replacement, gastroscopy should be considered for checking the position of the tube and for any evidence of complications.

\section{Competing interests: None}

Endoscopy_UCTN_Code_CPL_1AH_2AI

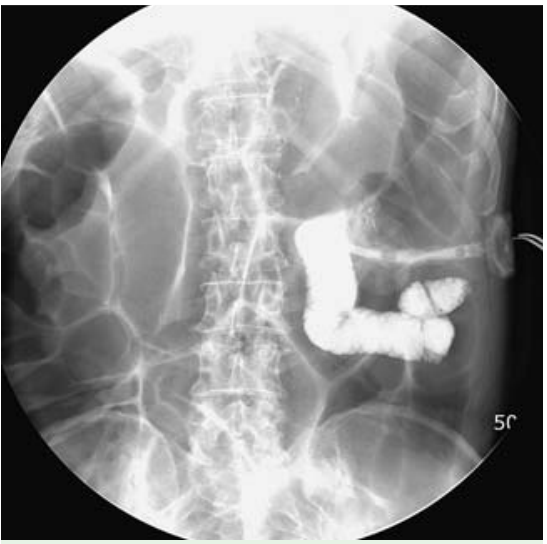

Fig. 2 Contrast study with Gastrografin showing the hub in the jejunum.

J. U. Lim, H. P. Shin, J. I. Lee, J. M. Cha,

\section{K. R. Joo}

Department of Internal Medicine, Kyung Hee University School of Medicine, Seoul, Korea

\section{References}

1 Milanchi S, Wilson MT. Malposition of percutaneous endoscopic-guided gastrostomy: Guideline and management. J Minim Access Surg 2008; 4: 1-4

2 Croaker GDH, Najmaldin AS. Laparoscopically assisted percutaneous endoscopic gastrostomy. Pediatr Surg Int 1997; 12: $130-$ 131

3 Pearce CB, Goggin PM, Collet J et al. The "cut and push" method of percutaneous endoscopic gastrostomy tube removal. Clin Nutr 2000; 191: $33-35$

Bibliography

DOI 10.1055/s-0029-1243981

Endoscopy 2010; 42: E116

(c) Georg Thieme Verlag KG Stuttgart · New York . ISSN 0013-726X

\section{Corresponding author}

\section{H. P. Shin, MD}

Department of Internal Medicine

Kyung Hee University East-West Neo

Medical Center

Sangil-dong, Gangdong-gu

Seoul, 134-090

Korea

Fax: +822-440-7046

megadoctor@medimail.co.kr 